\title{
Convallaria majalis L. S.I. (Asparagaceae Juss.) in Baikal Siberia
}

\author{
Alla Verkhozina $^{1}{ }^{*}$, Nina Kulakova $^{2}$, Denis Krivenko ${ }^{1}$, and Vladislav Murashko ${ }^{1}$ \\ ${ }^{1}$ Siberian Institute of Plant Physiology \& Biochemistry SB RAS, Irkutsk, Russia \\ ${ }^{2}$ Limnological Institute SB RAS, Irkutsk, Russia
}

\begin{abstract}
An interspecies diversity is a principal question for understanding of variability, geographical distribution and evolutionary history of the genus Convallaria. Considering the C. majalis s.str. and C. keiskei as the Eurasian species with overlapping morphological features there are scarce data on their genetic variability. The molecular genetic analysis of nuclear ITS1-2 marker, chloroplast gene fragments $\operatorname{trn} \mathrm{L}-\operatorname{trn} \mathrm{F}$ and maturase $\mathrm{K}$ was used to study genetic structure of 112 Convallaria specimens collected throughout Eurasia. The maturase $\mathrm{K}$ gene based results were shown to be the most efficient to resolve genetic structure of studied species. Three main haplotypes namely ancestral East Asian, South European-Caucasian and North European were dominant across geographical ranges of species C. keiskei, C. transcaucasica and C. majalis, respectively. Moreover, three minor haplotypes Khankai, Korean, and Manchurian were identified from nucleotide analysis. All three main haplotypes of Convallaria were found In Baikal Siberia. The proposed approach was sufficient to resolve an origin and genetic relations of local populations of Convallaria in the Irkutsk Region. Detected low level of genetic differences in analyzed species allows considering the single species $C$. majalis in Eurasia.
\end{abstract}

Within the genus Convallaria L. (Asparagaceae Juss.), three species are distinguished on the globe: C. majalis L. s.str. (mainly Europe), C. keiskei Miq. (North and East Asia), C. pseudomajalis W.Bartram $=C$. montana Fernald (North America). In Russia C. transcaucasica Utkin ex Grossh. and C. manschurica (Kom.) Knorring were previously distinguished. Presently, the first refers to $C$. majalis, the second is synonymous with C. keiskei. It is believed that three currently accepted species have isolated ranges, but their morphological differences are negligible. The number of chromosomes in the entire range of the genus is $2 n=38$.

For Baikal Siberia, two species of Convallaria are known. Specimens from the Irkutsk Region are identified as C. majalis s.str., and specimens from the Zabaykalsky Krai are referred to C. keiske [1] (as C. manschurica in the «Flora of Siberia» [2]) although they differ slightly morphologically.

The indigenous nature of Convallaria in the Zabaykalsky Krai is not in doubt, while the origin of the populations in the Irkutsk Region is ambiguous.

\footnotetext{
*Corresponding author: allaverh@list.ru
} 
According to the «Flora of Siberia» [2] C. majalis is known in Baikal Siberia for three localities: Lake Baikal, the vicinity of Irkutsk city, and Mezhdugranka village of Ziminsky District.

Probably, the herbarium specimen of Convallaria from Lake Baikal was collected by the member of the Irkutsk Medical Department Kruhse (Kruse; years of life 1799-1835) (LE01013855) (fig. 1). It was collected in the first half of the 19th century, but do not have an exact date. On the label, in addition to the collector's name, only the word Baikal is present, so the specimen could be collected not only in the Irkutsk Region, but also in the Republic of Buryatia and even in the Zabaykalsky Krai.

In the middle of the 19th century, Convallaria was collected by N.S. Turczaninow "Sibiria, pr.[ope] Irkutium" (LE01013857) (fig. 2) in the vicinity of Irkutsk but the herbarium label did not have an exact date also. In the "Flora baicalensi-dahurica» Turczaninow [3] cited Convallaria only for the Transbaikal territory as C. majalis.

The only extant population of Convallaria in the Irkutsk Region, that has no obvious signs of other than local origin, is located in the abandoned Mezhdugranka village of Ziminskiy District. In 1975, when Convallaria was found there, the specimens were identified as C. keiskei [4], but later, Vlasova [2] assigned them to C. majalis s.str.

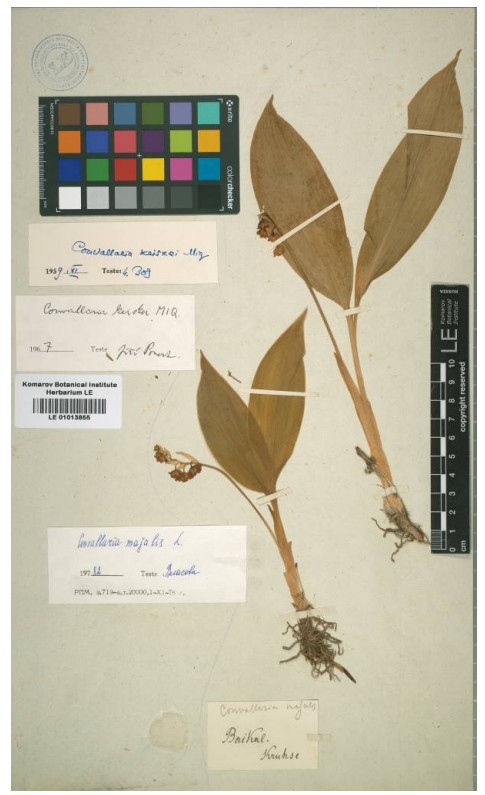

Fig. 1. The first herbarium specimen of Convallaria majalis from Baikal Siberia (LE01013855!).

The origin of this population was interpreted ambiguously from the very beginning and it was extensively discussed by the first researchers of the population [4] as the arguments were both for the anthropogenic and the relict origin of the population.

C. majalis was listed in the first edition of the Red Book of the Irkutsk Region [5] but was later excluded because this species is widely cultivated, feral and naturalized in the region. Currently, due to the invasive activity of the species in some regions of Siberia, $C$. majalis is included in the list of invasive and potentially invasive species of the Siberian Federal District [6].

The molecular genetics methods were applied to clarify the species affiliation and an origin of populations in the territory of Baikal Siberia as well as the genetic diversity of Convallaria in Eurasia. The analysis of $\operatorname{trn} \mathrm{L}-\mathrm{F}$, mat $\mathrm{K}$ chloroplast gene fragments and the genomic translated spacers ITS1-2 showed that the matK gene was the most informative 
marker. The genetic network of haplotypes was evaluated from the analysis of nucleotide and translated amino acid sequences of this gene.

For comparative analysis, we used samples from eleven Herbaria (IRK, LE, MHA, MW, NS, NSK, SVER, TK, VBGI, VLA and WIR) and specimens collected in the field. In addition to samples from the Baikal Region (Irkutsk Region and Zabaykalsky Krai), samples from the Western Siberia (Tomsk Region), European part of Russia, Crimea, Caucasus and Far East, Denmark, China, Mongolia, Norway, Ukraine, France, Sweden, Estonia, and Finland were included in the analysis, as well as sequences of specimens from UK, Italy, China, Korea and Japan from the GenBank (https://www.ncbi.nlm.nih.gov/). Altogether, there were 112 sequences of 507 nucleotides in length.

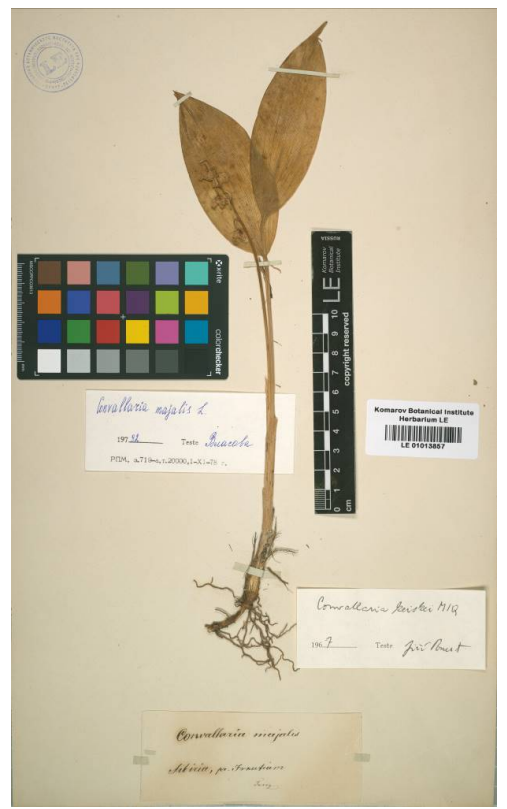

Fig. 2. Herbarium specimen of Convallaria majalis collected by N.S. Turczaninow in the vicinity of Irkutsk city (LE01013857!).

Unfortunately we did not have any samples or data on Convallaria from North America therefore our conclusions at the moment concern only Eurasia.

For the molecular genetic analysis, dried leaves $\left(10 \mathrm{~mm}^{2}\right)$ were crushed using pestles and used to isolate DNA using the modified Doyle \& Dickson technique [7]. The fragment of the chloroplast gene encoding maturase K (matK) was amplified by PCR using primers F_matK 5'-GAAATCTTRGTTCAAATYCTTC-3' and R_matK 5'CGTACAGTACTTTTTRTGTTTAC-3'. The amplification conditions were as follows: initial denaturation at $94{ }^{\circ} \mathrm{C}$ for 3 minutes, followed by 30 PCR cycles: denaturation at $94{ }^{\circ} \mathrm{C}$ for 1 minute, annealing of primers at $48{ }^{\circ} \mathrm{C}$ for 1 minute and elongation at $72{ }^{\circ} \mathrm{C}$ for 1 minute, post-elongation at $72{ }^{\circ} \mathrm{C}$ for 5 minutes. PCR was performed with the "BioLabMix" PCR-kit (Russia, Novosibirsk) with Bio-RadT100 Thermal Cycler (USA). The reaction products were analyzed in a 1\% agarose gel. A band of the expected size (890 bp) was cut out and cleaned. Sequencing was done at Synthol CJSC (Moscow, Russia). The BioEdit 7.0.7.1 program [8] and the ClustalW algorithm [9] were used for alignment construction and editing. The obtained nucleotide sequences were compared with the GenBank database using the BLAST search algorithm (https://blast.ncbi.nlm.nih.gov/Blast.cgi). 
Analysis of genetic diversity was performed using the Network 10.0.0.0 program [10] for the nucleotide and amino acid sequence data sets.

Based on the analysis of nucleotide sequences, six haplotypes were indicated among the Eurasian samples C. majalis s.l. (fig. 3) and three of them were dominant variants represented by a significant number of samples. There is the main ancestral East Asian haplotype (1); the other two Western haplotypes are the South European-Caucasian (2) and North European haplotypes, respectively (3).

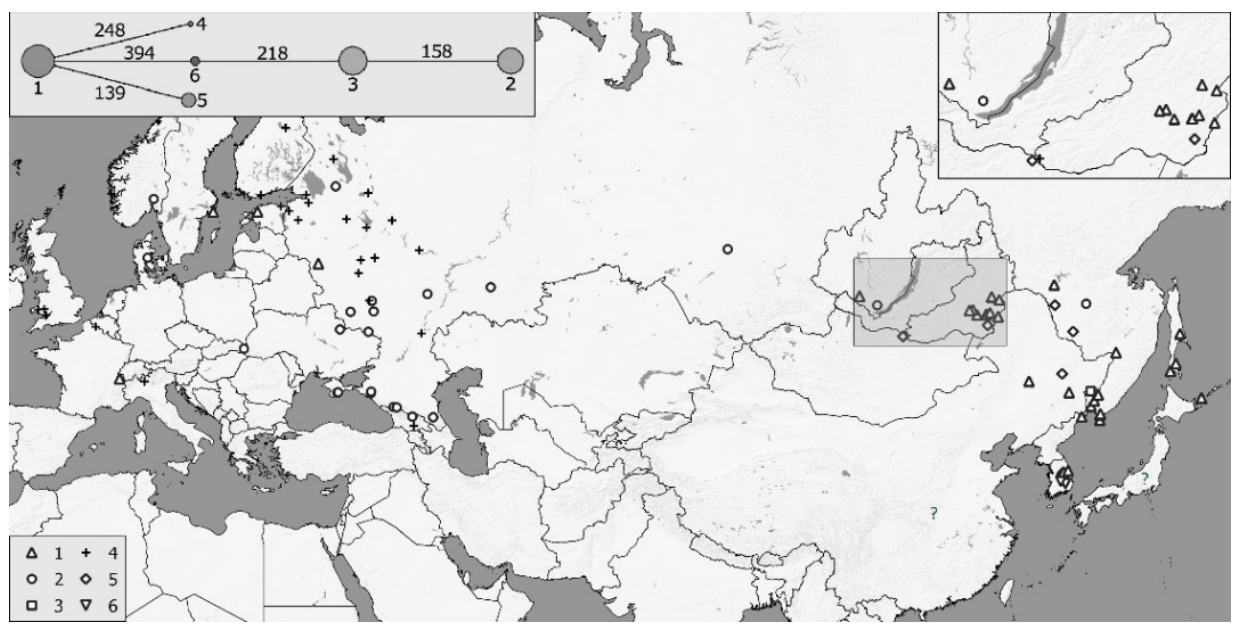

Fig. 3. Distribution of Convallaria haplotypes across Eurasia based on analysis of the matK gene nucleotide sequences. Numbers 1-6 and color mark different haplotypes (description in the text). The figure at the top left shows the haplotypes distribution scheme, where the numbers indicate the positions of nucleotide substitutions in the gene fragment under study.

These detected genetic variants are relatively well compatible with their geographical distribution and with described three geographical varieties (species or subspecies) of Convallaria. Although, three haplotypes are shown to be dominating in their specific geographic area, several samples did not correspond to this distribution pattern that could be due to human activities.

Based on the analysis of nucleotide sequences, in addition to the three dominant haplotypes, three minor haplotypes were identified. All of them were East Asian genetic variants within the East Asian type. We referred them as Khankai (4), Korean (5), and Manchurian (6) haplotypes according to the geographic origin of the samples.

The Khankai haplotype was represented by the only specimen from the Khankai District of the Primorsky Krai. Seven samples from the Priargunsky District of the Zabaykalsky Krai, Zavitinsky and Shimanovsky Districts of the Amur Region, South Korea, Mongolia and China belong to the Manchurian haplotype. The Korean haplotype is represented by three sequences from the Genbank database.

Not all samples of dominant haplotypes confirmed the distribution pattern fixed in the literature, which we expected from preliminary data. So a number of representatives of the ancestral almost exclusively East Asian haplotype were collected in Europe. Several samples belonging to the South European and Caucasian haplotype were collected from $55^{\circ}$ to $60^{\circ} \mathrm{N}$, which is much north of the main geographic range of this haplotype. At the same time, the southernmost specimen of those analyzed was collected in the Tetritskaro District of Georgia and was initially identified as C. transcaucasica, as well as two Northeast Asian specimens from the Krasnochikoysky District of the Zabaykalsky Krai (C. keiskei) and from Manchuria (C. manschurica), belonging to Northern European haplotype. 
Analysis of amino acid sequences confirmed the presence of the three dominant Convallaria haplotypes in Eurasia. As expected, it revealed a smaller number of haplotypes, only four, compared with six detected on the basis of nucleotide sequences (fig. 3 ) and showed the same geographical distribution (fig. 4). All samples from Eastern Asia belonged to the same variant, except one sample from the Khankai region, which stands out as a separate haplotype in both cases.

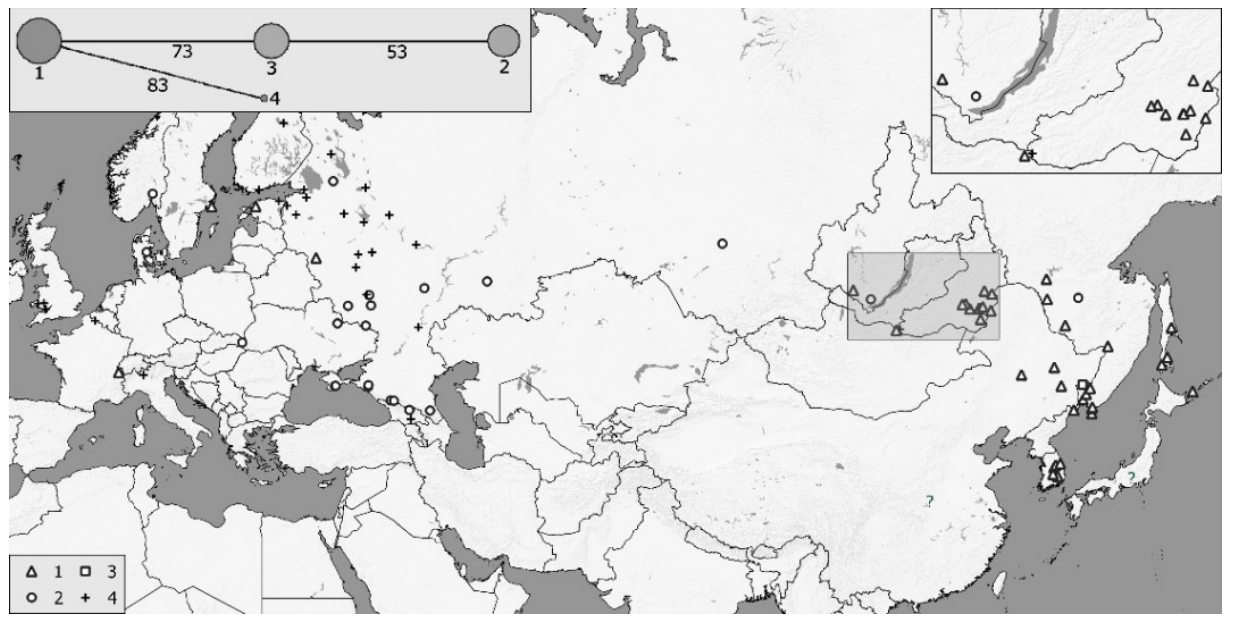

Fig. 4. Distribution of Convallaria haplotypes across Eurasia based on comparing the amino acid sequences of the matK proteine. Numbers $1-4$ and color mark different haplotypes (description in the text). The figure at the top left shows the haplotypes distribution scheme, where the numbers indicate the positions of nucleotide substitutions in the gene fragment under study.

Based on the translated amino acid sequence analysis only one minor haplotype was detected, the Khankai haplotype. The genetic polymorphism observed in East Asia haplotype of Convallaria has not yet been reflected in a change in the amino acid composition of the maturase $\mathrm{K}$ protein.

All three dominant and one minor (Manchurian) haplotypes were noted in Baikal Siberia. The populations from the Zabaykalsky Krai belong mainly to the ancestral haplotype, and also Manchurian and Northern European haplotypes represent. The ancestral and South European-Caucasian haplotypes are found in the Irkutsk Region:

The only modern population of Convallaria in the Irkutsk region, which has no obvious signs of alien origin, is located in the abandoned Mezhdugranka village of the Ziminsky District. According to the analysis of the $\operatorname{trn} \mathrm{L}-\mathrm{F}$ and $m a t \mathrm{~K}$ genes, it belongs to the ancestral haplotype (respectively, C. keiskei). In our opinion, it gives reason to consider this population to be indigenous. The appearance of Convallaria there is most likely not connected with its escaping cultivation, however, it is difficult to judge whether it is relict at the moment. Applying of microsatellite markers should be used to resolve this issue.

Specimens from the introduced and invasive populations in Irkutsk (as well as Tomsk) are combined with samples from the South Europe and the Caucasus into the South European-Caucasian haplotype ( $C$. majalis s.str.). We can assume that two microspecies inhabit the territory in the Irkutsk Region.

In this way, at the present stage the identification of Convallaria by geographical feature does not work, as well as morphological differences do not allow distinguishing haplotypes. Perhaps, before the wide cultivation of Convallaria, the haplotypes were more precisely separated geographically.

It seems to us reasonable to use the species name $C$. majalis for the entire Eurasian range of the genus, as was done, for example, in «Flora of China» [11], where C. keiskei, C. 
keiskei var. trifolia Y.C.Chu \& J.F.Li and C. majalis var. manshurica Kom. are synonymous with this species. 388084 .

The reported study was funded by RFBR and Government of Irkutsk Region - grant 17-44-

\section{References}

1. K.S. Baikov (ed.), Conspectus of the flora of Asian Russia: vascular plants. (Publishing House SB RAS, Novosibirsk, 2012)

2. N.V. Vlasova, Convallaria L., Flora Sibiri (Nauka, Novosibirsk, 1987)

3. N. Turczaninov, Flora Baicalensi-Dahurica, seu, Descriptio plantarum in regionibus Cis- et Transbaicalensibus atque in Dahuria sponte nascentium, 2 (Mosquae, A. Semen, 1856)

4. L.V. Bardunov, V.V. Telyat'ev, Botanicheskiy zhurnal, 61, 1290-1294 (1976)

5. Red Book of the Irkutsk region: Vascular plants. (Oblmashinform, Irkutsk, 2001)

6. A.L. Ebel, T.O. Strelnikova, A.N. Kupriyanov O.A. Anenkhonov, E.S. Ankipovich, E.M. Antipova, A.V. Verkhozina, A.N. Efremov, E.Yu. Zykova, S.I. Mikhailova, N.V. Plikina, S.V. Ryabovol, M.M. Silantyev, N.V. Stepanov, T.A. Terekhina, O.D. Chernova, D.N. Shaulo, Bulletin 'of the main botanical garden, 200, 52-62 (2014)

7. J.J. Doyle, E.E. Dickson, Taxon 36, 715-722 (1987)

8. T.A. Hall, Nucl. Acids. Symp. Ser., 41, 95-98 (1999)

9. J.D. Thompson, D.G. Higgins, T.J. Gibson, Nucleic Acids Res., 22, 4673-4680 (1994)

10. H.-J. Bandelt, P. Forster, A. Röhl, Mol. Biol. Evol., 16, 37-48 (1999)

11. L.L. Shu, L. Songyun, M.N. Tamura, Convallaria L., Flora of China (Science Press \& MBG Press, Beijing \& St Louis, 2000) 